\title{
Review Article \\ Genotyping the High Altitude Mestizo Ecuadorian Population Affected with Prostate Cancer
}

\author{
Andrés López-Cortés, ${ }^{1}$ Alejandro Cabrera-Andrade, ${ }^{1}$ \\ Carolina Salazar-Ruales, ${ }^{1}$ Ana Karina Zambrano, ${ }^{1}$ Santiago Guerrero, ${ }^{2}$ \\ Patricia Guevara, ${ }^{1}$ Paola E. Leone, ${ }^{1}$ and César Paz-y-Miño ${ }^{1}$ \\ ${ }^{1}$ Centro de Investigación Genética y Genómica, Facultad de Ciencias de la Salud Eugenio Espejo, \\ Universidad Tecnológica Equinoccial, Avenue Mariscal Sucre, 170129 Quito, Ecuador \\ ${ }^{2}$ Gene Regulation, Stem Cells and Cancer Programme, Centre for Genomic Regulation (CRG), \\ The Barcelona Institute for Science and Technology, Universitat Pompeu Fabra (UPF), Dr. Aiguader 88 Street, 08003 Barcelona, Spain
}

Correspondence should be addressed to Andrés López-Cortés; aalc84@gmail.com

Received 21 December 2016; Accepted 15 May 2017; Published 8 June 2017

Academic Editor: Gianluigi Taverna

Copyright ( 2017 Andrés López-Cortés et al. This is an open access article distributed under the Creative Commons Attribution License, which permits unrestricted use, distribution, and reproduction in any medium, provided the original work is properly cited.

\begin{abstract}
Prostate cancer (PC) is the second most commonly diagnosed type of cancer in males with 1,114,072 new cases in 2015. The MTHFR enzyme acts in the folate metabolism, which is essential in methylation and synthesis of nucleic acids. MTHFR C677T alters homocysteine levels and folate assimilation associated with DNA damage. Androgens play essential roles in prostate growth. The SRD5A2 enzyme metabolizes testosterone and the V89L polymorphism reduces in vivo SRD5A2 activity. The androgen receptor gene codes for a three-domain protein that contains two polymorphic trinucleotide repeats (CAG, GGC). Therefore, it is essential to know how PC risk is associated with clinical features and polymorphisms in high altitude Ecuadorian mestizo populations. We analyzed 480 healthy and 326 affected men from our three retrospective case-control studies. We found significant association between MTHFR C/T (odds ratio $[\mathrm{OR}]=2.2 ; P=0.009)$, MTHFR $\mathrm{C} / \mathrm{T}+\mathrm{T} / \mathrm{T}(\mathrm{OR}=2.22 ; P=0.009)$, and PC. The SRD5A2 A49T substitution was associated with higher pTNM stage $(\mathrm{OR}=2.88 ; P=0.039)$ and elevated Gleason grade $(\mathrm{OR}=3.15 ; P=0.004)$. Additionally, patients with $\leq 21 \mathrm{CAG}$ repeats have an increased risk of developing PC (OR $=2.99 ; P<0.001)$. In conclusion, genotype polymorphism studies are important to characterize genetic variations in high altitude mestizo populations.
\end{abstract}

\section{Epidemiology of Prostate Cancer}

Prostate cancer (PC) represents a significant health problem that involves the progressive accumulation of environmental, hormonal, genetic, and hereditary factors [1]. PC is the second most commonly diagnosed type of cancer in males, representing $\sim 15 \%$ of all new cancer cases in $2015(1,114,072$ cases) [2]. Worldwide, the areas with a higher incidence of PC cases per 100,000 inhabitants are Oceania (101.9), North America (97.2), and Western Europe (94.9) [2-4]. In the Latin America region, $\mathrm{PC}$ was the most common malignancy diagnosed among males. The incidence of PC varied by 6 fold across this region during the period from 2003 to 2007. The highest age-standardized rates were observed in French
Guyana (147.1) and Brazil (91.4) and the lowest ones were in Mexico (28.9) and Cuba (24.3). PC was one of the two leading causes of cancer deaths in males in Latin America, except in Chile, Argentina, Colombia, and El Salvador where it ranked third. Mortality rates varied by 4 -fold, with the highest rates seen in Belize (28.9), Uruguay (21.8), and Cuba (24.1) and the lowest ones in Peru, Nicaragua, and El Salvador (rates between 6.8 and 9.7) [5]. In Ecuador 33\% of all carcinoma diagnoses in males are prostate cancer, with an increase in the incidence from 23.7 per 100,000 inhabitants in 1985 to 54.4 in $2012[2-4,6]$. Furthermore, the mortality rate associated with PC was 18.12 per 100,000 inhabitants in Ecuador in 2012 [2$4,6,7]$. 
TABLE 1: Different NGS techniques used in prostate cancer studies.

\begin{tabular}{|c|c|c|c|}
\hline Finding & NGS technology & Year & Reference \\
\hline $\begin{array}{l}\text { Deletion at chromosome } 3 \text { p14 implicates FOXP1, RYBP, } \\
\text { and SHQ1 as potential cooperative tumor suppressors }\end{array}$ & WES & 2010 & {$[21]$} \\
\hline $\begin{array}{l}\text { TMPRSS2-ERG, CTAGE5-KHDRBS3, and } \\
\text { USP9Y-TTTY15 fusions, long noncoding RNAs (long } \\
\text { ncRNAs), alternative splicing, and somatic mutations }\end{array}$ & $\begin{array}{l}\text { RNA } \\
\text { sequencing } \\
\text { WGS }\end{array}$ & 2011, 2012 & {$[16,18]$} \\
\hline SPOP, FOXA1, and MED12 mutations & WES & 2012 & {$[20]$} \\
\hline Variant at $8 \mathrm{q} 24$ and HOXB13 & WGS & 2012 & [22] \\
\hline Rearrangements, translocations, and deletions & WGS & 2013 & [23] \\
\hline $\begin{array}{l}\text { ADP-regulated signaling pathways-inhibitions of } \\
\text { Wnt/B catenin signaling pathways }\end{array}$ & $\begin{array}{l}\text { RNA } \\
\text { sequencing }\end{array}$ & 2014 & {$[17]$} \\
\hline $\begin{array}{l}\text { Heterogeneity of AR gene expression, mutations, and } \\
\text { splicing variants }\end{array}$ & $\begin{array}{l}\text { Single-cell RNA } \\
\text { seq }\end{array}$ & 2015 & {$[19]$} \\
\hline
\end{tabular}

\section{Genomic Landscape in Prostate Cancer}

Due to the fact that cancer rates are increasing every year, new technologies are being applied to detect, manage, and treat it according to the patient. Consequently, in the last years, next-generation sequencing (NGS) has emerged in order to provide a comprehensive characterization in cancer and other diseases [8]. Moreover, NGS technology allows for the identification of base substitution, insertion-deletion, copy number variance, and structural alteration with good sensitivity in cancer [9]. Some studies using NGS have been carried out, obtaining relevant information in breast cancer, lung cancer, ovarian cancer, colorectal cancer, and melanoma [10]. It is important to mention that there are available various NGS techniques that could be applied in cancer, specifically in prostate cancer.

2.1. Whole-Genome Sequencing (WGS). The WGS is the most complex technique based on the genomic DNA extraction from amplified and sequenced cancerous tissue giving, as a result, the somatic variations, such as mutations, insertions, and deletions, copy number variants, and rearrangements, among others. Nevertheless, the large amount of information that can be obtained with WGS, depending on the application (mutations, structural rearrangements, or others), needs time and a big coverage (100-200-fold coverage) that are translated into cost [11].

2.2. Whole-Exome Sequencing (WES). WES is based on the protein coding genes (exome) present in 1-2\% of the human genome. It can give huge amounts of variation data of all coding regions of known genes. WES is cheaper than WGS because it analyzes a sequence of interest 70-100-fold coverage in order to identify the presence of mutations [12].

2.3. RNA Sequencing. RNA sequencing needs an additional step, which is the reverse transcription from cDNA, but it can give important data in cancer analysis, such as mutations, dysregulated genes, variants, and the level of expression. However, RNA sequencing experiments can be affected by technical effects in the sequencing steps and by contamination [13].
2.4. Single-Cell RNA Sequencing. The heterogeneity of cancer can be completely understood by single-cell RNA sequencing and it can be used as an instrument for clinical decisions. Besides, it identifies driver mutations, differentially expressed genes when it is compared with normal tissue, and drug resistance and it can also suggest other therapeutic alternatives [11]. The technique includes the separation of tumor cells by laser capture, cell sorting (FACS), or microfluidics, followed by cell isolation.

Furthermore, PC has been considered a challenge in diagnosis and prognosis because of the highly heterogeneous nature and the limited sample of tumor tissue. Consequently, merging traditionally diagnostic methods with NGS can diagnose PC with greater accuracy. There are plenty of publications regarding studies in PC that reported using NGS through whole-genome and whole-exome technology and RNA sequencing, among others. For instance, Robinson et al. (2015) reported that specific AR mutations can be linked to clinical phenotypes in order to determine the mutations that are responsible for resistance to therapy and the $40 \%-60 \%$ of the cases showed abnormalities of AR, ETS genes, TP53, and PTEN [14]. Another study is the one published by Lohr et al. (2014) who characterized circulating tumor cells by WES, and the variants were in concordance with the tumor biopsies; the used methodology gave an alternative because of the type of sample even though both techniques must be combined in order to reduce false-positives and reveal new mutations [15]. Another study is the one published by Berger et al. (2011), where they identified 3,866 putative somatic base mutations, mutated genes, and MAGI2 genomic rearrangements that are directed to improve the diagnostic and patient stratification by PI3 pathways [16]. There are other PC studies that include different NGS techniques in order to determine the following: signaling pathways, genomic alterations, repair defects, and gene merging (Table 1).

The main genetic alterations reported for prostate cancer are as follows: (a) merging: the main merging described is the one between TMPRSS2 and ETS family verified by various NGS techniques achieving the same result, constituting a powerful tool for diagnostic PC [16-18]; (b) mutations: P53 mutation is linked in most tumor types including hereditary. 
It is involved in the response of cellular stress, cell survival, apoptosis, DNA repair, or change in the metabolism [11]; (c) pathways deregulations: there are studies that reported proliferative pathways that may promote cancer proliferation in the prostate. The AR abnormality is the most mentioned one in bibliography because it can modulate NCOA2, NCOR2, and regulatory elements like FOXA1 [16, 19-21]. Another signaling that can be found in prostate cancer is implied in cell growth and proliferation and apoptosis-like PI3K and PTEN [9]; and (d) variants and rearrangement: one variant described was at the $8 \mathrm{q} 24$ locus being a prostate cancer risk variant [22]. Furthermore, CHD1 regulates the chromatin state and its rearrangements are associated with more copy number variants [23].

\section{The Steroid $5 \alpha$-Reductase Type II Gene (SRD5A2) and Prostate Cancer Risk}

The association of polymorphisms in the steroid $5 \alpha$-reductase type II (SRD5A2) gene with prostate cancer risk in the high altitude mestizo Ecuadorian population was studied in 2009 by Paz-y-Miño et al. [24]. The steroid 5 $\alpha$-reductase type II enzyme is responsible for metabolizing the main androgenic hormone called testosterone that helps in the growth and development of the prostate. Due to the activity of the type II enzyme, testosterone is irreversibly converted into dihydrotestosterone (DHT), which is the reduced and metabolically more active form [25]. DHT then binds to the androgen receptor for the transactivation of androgensensitive elements as well as those that control cell proliferation. The SRD5A2 gene encodes the steroid $5 \alpha$-reductase type II enzyme whose enzymatic activity may vary in such a way that it influences the incidence of PC [26].

The SRD5A2 gene plays an essential role in the induction of androgenic stimulation in the prostate and is highly polymorphic [27]. Hsing et al. suggest that genetic variations of this gene such as A49T and V89L are commonly studied and related to this type of cancer [26]. The V89L polymorphism, a missense mutation that substitutes leucine for valine at codon 89 , identified by Makridakis et al., was reported to reduce in vivo steroid $5 \alpha$-reductase activity [28]. Also, they found this substitution to be more common among Asians and believed this may explain the low risk for prostate cancer within this population. Another common polymorphism that has been reported to vary noticeably across populations is A49T, which results in an alanine residue at codon 49 being replaced with threonine. This missense substitution may enhance the conversion of testosterone into dihydrotestosterone because of increased enzymatic activity in vitro and has been associated with a higher risk of advanced prostate cancer in African American and Hispanic men living in the United States [29]. A total of 258 individuals, including 114 individuals with a previous diagnosis of prostate cancer and 144 control men, were analyzed to determine the association of SRD5A2 gene polymorphisms with the pathological characteristics of the tumor and the risk of PC in the high altitude mestizo Ecuadorian population.

The affected group had a median age of 70 years. 58\% of the individuals were between 46 and 93 years old and
$16 \%$ were older than 80 years. The pathological features of prostate tumors were quite variable, and the pathological stage of the tumor in most patients was moderate while $27 \%$ of the cases were diagnosed with advanced cancer. The $65 \%$ of the cases had serum prostate specific antigen levels greater than $10 \mathrm{ng} / \mathrm{mL}$. The $23 \%$ of the individuals presented seminal vesicle invasion and $14 \%$ of the cases had positive surgical margins. The sixth level of Gleason grade is characterized because the cells are differentiated, in such a way that $59 \%$ of the cases have this score. There were significant differences between the tumor status and the presence of V89L polymorphism with the VV or VL genotype, where the LL genotype presented a highly significant reduction regarding the development of a high tumor stage $(\mathrm{OR}=0.11$, $95 \% \mathrm{CI}=0.04-0.27$, and $P<0.001)$. While the higher $\mathrm{pTNM}$ stage $(\mathrm{OR}=2.88,95 \% \mathrm{CI}=1.15-7.21$, and $P=0.039)$ and an elevated Gleason grade $(\mathrm{OR}=3.15,95 \% \mathrm{CI}=1.13-8.78$, and $P=0.043$ ) are associated with the A49T polymorphism.

Nam et al. and $\mathrm{Li}$ et al. showed that the $\mathrm{V}$ allele of the V89L polymorphism in the SRD5A2 gene was associated with PC risk because this $\mathrm{V}$ allele may encode for $5 \alpha$-reductase variants with different activities, which are likely attributed to altered mRNA stability, which could alter the steroid $5 \alpha$ reductase protein, leading to an increased cell division and, therefore, a higher likelihood of carcinogenesis [30, 31].

The genotype and allelic distribution of the V89L polymorphism in the Ecuadorian population support the hypothesis of the $\mathrm{L}$ allele having a protective status because of its suggested lower $5 \alpha$-reductase enzymatic activity among men with the LL genotype $[26,28,32,33]$. Other studies, however, have conversely found the LL genotype of the SRD5A2 V89L polymorphism to significantly increase the risk of PC [3437]. Differences in genetic, dietary, and environmental factors among populations may explain the inconsistent results obtained in different studies. Our study also shows that men carrying the A49T variant have prostate tumors with a higher pathologic tumor-lymph node-metastasis (pTNM) stage (OR $=2.87 ; 95 \% \mathrm{CI}=1.15-7.21 ; P=0.039)$ and a high Gleason grade $(\mathrm{OR}=3.15 ; 95 \% \mathrm{CI}=1.13-8.78 ; P=0.044)$. Our results agree with those of Jaffe et al., who reported the $\mathrm{T}$ allele to be linked to a greater frequency of extracapsular disease and a higher pTNM stage [38]. The genotype and allelic distribution are shown in Table 2, the OR test associated with polymorphisms is shown in Table 3 , and the OR test associated with clinical data is shown in Table 4.

According to the 1000 Genomes' Project (Phase 3), the allele frequencies of the SRD5A2 V89L polymorphism are $G=0.255$ and $C=0.745$ in Colombians, $G=0.406$ and $C=0.594$ in Peruvians, $G=0.233$ and $C=0.766$ in Iberians, $G=0.389$ and $C=0.611$ in Japanese, $G=0.387$ and $C=0.613$ in Indians, $G=0.524$ and $C=0.476$ in Han Chinese, and $G=0.320$ and $C=0.680$ in the mestizo Ecuadorian population [39]. Also, the allele frequencies of the SRD5A2 A49T polymorphism are $C=0.979$ and $T=0.021$ in Colombians, $C=0.982$ and $T=0.018$ in Peruvians, $C=0.981$ and $T=0.019$ in Iberians, $C=1.000$ and $T=0.000$ in Japanese, $C=1.000$ and $T=0.000$ in Indians, $C=1.000$ and $T=0.000$ in Han Chinese, and $C=0.550$ and $T=0.450$ in the mestizo Ecuadorian population [39]. 
TABLE 2: Genotype distribution and allele frequency of polymorphisms in SRD5A2, MTHFR, and AR genes in high altitude Ecuadorian population with prostate cancer.

\begin{tabular}{|c|c|c|c|c|c|c|c|c|}
\hline \multirow{2}{*}{ Gene } & \multirow{2}{*}{ Polymorphism } & \multirow{2}{*}{ Genotype } & \multicolumn{3}{|c|}{ Genotypic frequency } & \multicolumn{3}{|c|}{ Allele frequency } \\
\hline & & & Control & Case & All & Control & Case & All \\
\hline \multirow{6}{*}{ SRD5A2 } & \multirow{3}{*}{ A49T } & $\mathrm{A} / \mathrm{A}$ & 0.347 & 0.289 & 0.322 & 0.674 & 0.553 & 0.627 \\
\hline & & $\mathrm{A} / \mathrm{T}$ & 0.653 & 0.526 & 0.597 & & & \\
\hline & & $\mathrm{T} / \mathrm{T}$ & 0.000 & 0.184 & 0.081 & 0.326 & 0.447 & 0.373 \\
\hline & \multirow{3}{*}{ V89L } & $\mathrm{V} / \mathrm{V}$ & 0.153 & 0.404 & 0.264 & 0.469 & 0.684 & 0.564 \\
\hline & & $\mathrm{V} / \mathrm{L}$ & 0.632 & 0.561 & 0.601 & & & \\
\hline & & $\mathrm{L} / \mathrm{L}$ & 0.215 & 0.035 & 0.136 & 0.531 & 0.316 & 0.436 \\
\hline \multirow{3}{*}{ MTHFR } & \multirow{3}{*}{ C677T } & $\mathrm{C} / \mathrm{C}$ & 0.473 & 0.288 & 0.383 & 0.732 & 0.639 & 0.687 \\
\hline & & $\mathrm{C} / \mathrm{T}$ & 0.518 & 0.702 & 0.607 & & & \\
\hline & & $\mathrm{T} / \mathrm{T}$ & 0.009 & 0.010 & 0.009 & 0.268 & 0.361 & 0.313 \\
\hline \multirow{4}{*}{$\mathrm{AR}$} & \multirow{2}{*}{ CAG repeats } & $\geq 22$ CAGs & 0.639 & 0.372 & 0.484 & & & \\
\hline & & $\leq 21 \mathrm{CAGs}$ & 0.361 & 0.628 & 0.516 & & & \\
\hline & \multirow{2}{*}{ GGC repeats } & $\geq 17$ GGCs & 0.389 & 0.281 & 0.329 & & & \\
\hline & & $\leq 16 \mathrm{CAGs}$ & 0.611 & 0.719 & 0.671 & & & \\
\hline
\end{tabular}

TABLE 3: Association between genetic polymorphisms and prostate cancer risk among cases and controls.

\begin{tabular}{|c|c|c|c|c|c|}
\hline \multirow{2}{*}{ Gene } & \multirow{2}{*}{ Polymorphism } & \multirow{2}{*}{ Genotype } & \multicolumn{3}{|c|}{ Case versus control } \\
\hline & & & OR & $95 \% \mathrm{CI}$ & $P$ value \\
\hline \multirow{8}{*}{ SRD5A2 } & \multirow{4}{*}{ A49T } & $\mathrm{A} / \mathrm{A}$ & & & Reference \\
\hline & & $\mathrm{A} / \mathrm{T}$ & 0.97 & $0.56-1.67$ & 1 \\
\hline & & $\mathrm{T} / \mathrm{T}$ & 0.40 & $0.31-0.52$ & 0.000 \\
\hline & & $\mathrm{A} / \mathrm{T}+\mathrm{T} / \mathrm{T}$ & 1.31 & $0.77-2.22$ & 0.394 \\
\hline & \multirow{4}{*}{ V89L } & $\mathrm{V} / \mathrm{V}$ & & & Reference \\
\hline & & $\mathrm{V} / \mathrm{L}$ & 0.34 & $0.19-0.61$ & \\
\hline & & $\mathrm{L} / \mathrm{L}$ & 0.06 & $0.02-0.20$ & \\
\hline & & $\mathrm{V} / \mathrm{L}+\mathrm{L} / \mathrm{L}$ & 0.27 & $0.15-0.48$ & 0.000 \\
\hline \multirow{4}{*}{ MTHFR } & \multirow{4}{*}{$\mathrm{C} 677 \mathrm{~T}$} & $\mathrm{C} / \mathrm{C}$ & & & Reference \\
\hline & & $\mathrm{C} / \mathrm{T}$ & 2.22 & $1.26-3.92$ & 0.008 \\
\hline & & $\mathrm{T} / \mathrm{T}$ & 1.73 & $0.11-28.73$ & 1 \\
\hline & & $\mathrm{C} / \mathrm{T}+\mathrm{T} / \mathrm{T}$ & 2.21 & $1.26-3.89$ & 0.008 \\
\hline \multirow{2}{*}{$\mathrm{AR}$} & \multirow{2}{*}{ CAG repeats } & $\geq 22$ CAGs & & & Reference \\
\hline & & $\leq 21 \mathrm{CAGs}$ & 2.99 & $1.79-5.01$ & 0.000 \\
\hline
\end{tabular}

OR, odds ratio.

TABLE 4: Association of prostate cancer risk with genotype polymorphisms and clinical features.

\begin{tabular}{|c|c|c|c|c|c|c|c|c|c|c|c|c|}
\hline \multirow{2}{*}{ Gene } & \multirow{2}{*}{ Polymorphism } & \multirow{2}{*}{ Genotype } & \multicolumn{2}{|c|}{ Gleason score } & \multirow{2}{*}{ OR } & \multirow{2}{*}{$95 \%$ CI } & \multirow{2}{*}{$P$ value } & \multicolumn{2}{|c|}{ Tumor stage } & \multirow{2}{*}{ OR } & \multirow{2}{*}{$95 \% \mathrm{CI}$} & \multirow{2}{*}{$P$ value } \\
\hline & & & $2-6$ & $7-10$ & & & & T1-T2b & $\mathrm{T} 2 \mathrm{c}-\mathrm{T} 4$ & & & \\
\hline \multirow{4}{*}{ SRD5A2 } & \multirow{2}{*}{$\mathrm{A} 49 \mathrm{~T}$} & $\mathrm{~A} / \mathrm{A}$ & 20 & 6 & & Reference & & 17 & 10 & & Reference & \\
\hline & & $\mathrm{A} / \mathrm{T}+\mathrm{T} / \mathrm{T}$ & 36 & 34 & 3.15 & $1.13-8.78$ & 0.044 & 26 & 44 & 2.88 & $1.15-7.21$ & 0.039 \\
\hline & \multirow{2}{*}{ V89L } & $\mathrm{V} / \mathrm{V}$ & 19 & 24 & & Reference & & 8 & 36 & & Reference & \\
\hline & & $\mathrm{V} / \mathrm{L}+\mathrm{L} / \mathrm{L}$ & 37 & 16 & 0.34 & $0.15-0.79$ & 0.020 & 36 & 17 & 0.11 & $0.04-0.27$ & 0.000 \\
\hline \multirow{2}{*}{ MTHFR } & \multirow{2}{*}{$\mathrm{C} 677 \mathrm{~T}$} & $\mathrm{C} / \mathrm{C}$ & 25 & 5 & & Reference & & 12 & 15 & & Reference & \\
\hline & & $\mathrm{C} / \mathrm{T}+\mathrm{T} / \mathrm{T}$ & 32 & 34 & 5.31 & $1.81-15.56$ & 0.003 & 33 & 35 & 0.85 & $0.35-2.08$ & 0.895 \\
\hline \multirow{2}{*}{ AR } & \multirow{2}{*}{ CAG repeats } & $\geq 22 \mathrm{CAGs}$ & 19 & 8 & & Reference & & 19 & 8 & & Reference & \\
\hline & & $\leq 21 \mathrm{CAGs}$ & 27 & 33 & 2.90 & $1.10-7.66$ & 0.05 & 20 & 40 & 4.75 & $1.77-12.72$ & 0.003 \\
\hline
\end{tabular}

OR, odds ratio. 
In conclusion, we found highly significant associations between two polymorphisms in the SRD5A2 gene. The V allele of the V89L polymorphism is associated with an increased risk, and the LL genotype has a protective role in the progression to a higher pTNM stage, while the TT homozygous genotype of the A49T polymorphism is associated with a higher pTNM stage and an elevated Gleason in the high altitude mestizo Ecuadorian population.

\section{The Folate-Metabolizing MTHFR Gene and Prostate Cancer Risk}

In 2013, López-Cortés et al. associated the folate-metabolizing genes with pathological characteristics of prostate cancer in the high altitude Ecuadorian mestizo population [40]. Regarding the folate cycle, the methylenetetrahydrofolate reductase (MTHFR), methionine synthase (MTR), and MTR reductase (MTRR) enzymes play an essential role in the folate metabolism [41], which is an important source for RNA and DNA synthesis and methylation [42]. The MTHFR enzyme controls a reaction of 5,10 methylenetetrahydrofolate to 5-methylenetetrahydrofolate [43-45], which is used as a methyl group donor for the remethylation of homocysteine to methionine, being a precursor of S-adenosylmethionine (SAM), essential in methylation of phospholipids, proteins, RNA, and DNA [41, 46, 47]. The remethylation of homocysteine to methionine is catalyzed by MTR in a reaction depending on vitamin $\mathrm{B}_{12}$ as an intermediary carrier of methyl group [48]. The MTR enzyme becomes inactive when the remethylation cofactor (vitamin $\mathrm{B}_{12}$ ) is oxidized by the MTRR enzyme [46, 49]. The MTRR enzyme catalyzes the regeneration of methylcobalamin, MTR cofactor, keeping the MTR active [50]. On the other hand, 5,10 -methylenetetrahydrofolate is used by the thymidylate synthase enzyme in the methylation of deoxyuridylate to deoxythymidylate, which is a source of thymidine required for DNA synthesis and repair [46].

Folate deficiency is associated with the rise in DNA rupture, chromosome damage, and formation of micronucleus in lymphocytes. These effects may depend on hereditary defects or be acquired in the absorption and metabolism of folic acid [51]. The MTHFR C677T single nucleotide polymorphism has been identified in the alteration of the levels of folates and homocysteine [52], triggering an alteration of the functioning of expressed proteins [46]. The presence of the allelic variants of the MTHFR C677T polymorphism causes reduced enzymatic activity, alteration in the homocysteine levels, and folate concentration in plasma [46, 50]. The MTHFR C677T variant has been associated with neural tube defects, cerebrovascular diseases [53, 54], coronary artery disease, venous thrombotic disease, and the rise in the risk of developing ovary cancer [55], esophagus cancer [56], gastric cancer [57], and prostate cancer [58]. On the contrary, a low risk of developing leukemia and colorectal cancer has been observed [59, 60]. A retrospective casecontrol study was conducted to establish the frequency of the C677T polymorphism in the MTHFR gene related to the folate metabolism, DNA synthesis and methylation, and their association with pathological characteristics in the high altitude mestizo Ecuadorian individuals with PC. Two hundred fourteen individuals altogether were analyzed. One hundred samples were taken from individuals diagnosed with PC after going through prostatectomy between 2004 and 2006. One the other hand, the control group was made up of 110 healthy men.

About the clinical-pathological parameters, $61 \%$ of the individuals affected by PC were aged between 63 and 79 years, whereas $16 \%$ were older than 79 years. Regarding pathological tumor stage, $30 \%$ of the cases were diagnosed with advanced cancer. Forty-one percent of the individuals had a Gleason score between 7 and 10 (poorly differentiated carcinoma). Concerning the PSA levels, $65 \%$ of the cases had a level higher than $10 \mathrm{ng} / \mathrm{mL}$. Fourteen percent of the individuals had positive surgical margins, whereas $23 \%$ of the cases showed positive invasion of the seminal vesicle. The Gleason grading system for PC is the dominant method around the world in research and daily practice. A common practice has been to translate Gleason score of 2-4 carcinoma as welldifferentiated, Gleason score of 5-6 as moderately differentiated, and Gleason scores of 7-10 as poorly differentiated [61]. Because there was no significant risk between the CT + TT genotypes and the Gleason score of 2-4 versus 5-6 $(\mathrm{OR}=$ $0.9 ; P=1$ ) and because there was significant risk between the Gleason score of $2-4$ versus $7-10(\mathrm{OR}=5.2, P=0.007)$, an association between the Gleason grade and the MTHFR C677T polymorphism was shown.

The MTHFR gene has been widely studied, and it was observed that the T/T677 genotype reduces the risk of colorectal cancer, acute lymphocytic leukemia, and malignant lymphoma [59, 62, 63]. Hypermethylation plays an important role in ontogenesis, silencing expressions of $\mathrm{CpG}$ islands in regions that promote tumor suppressor genes [64]. On the contrary, Heijmans et al. [47], Sharp and Little [65], Robien and Ulrich [66], Shen et al. [67], Song et al. [56], and Miao et al. [57] have observed association between the MTHFR C677T variant and different types of cancer [55]. For this reason, there is a continuous debate on the effects of the MTHFR C677T polymorphism on PC [41]. In our study, we found that the MTHFR C/T genotype is significantly risky in affected individuals with an OR of $2.2(P=0.008)$, being a possible association between this polymorphism and PC; therefore, these results were similar to those provided by Marchal et al. [68] and Van Guelpen et al. [69]. The genotype and allelic distribution are shown in Table 2 , the OR test associated with polymorphisms is shown in Table 3 , and the OR test associated with clinical data is shown in Table 4.

According to the 1000 Genomes' Project (Phase 3), the allele frequencies of the MTHFR C677T polymorphism are $G$ $=0.457$ and $A=0.543$ in Colombians, $G=0.565$ and $A=0.435$ in Peruvians, $G=0.556$ and $A=0.444$ in Iberians, $G=0.620$ and $A=0.379$ in Japanese, $G=0.897$ and $C=0.103$ in Indians, $G=0.534$ and $A=0.466$ in Han Chinese, and $G=0.640$ and $A=0.360$ in the mestizo Ecuadorian population [39].

In conclusion, the association between Gleason grade, MTHFR gene, and prostate cancer is an important contribution to understanding the different genetic behavior of cancer between the high altitude mestizo Ecuadorian population and populations worldwide. 


\section{The Androgen Receptor (AR) Gene and Prostate Cancer Risk}

In 2016, Paz-Y-Miño et al. positively associated the androgen receptor CAG repeat length polymorphism with the risk of prostate cancer in the high altitude Ecuadorian mestizo and indigenous populations [70]. This study was performed to determine the association between CAG and GGC repeats and the risk of PC and histopathological characteristics of prostate tumors. The prostate cell cycle is mediated by the interactions of the androgen receptor (AR) gene, which is located on chromosome Xq12 and encodes a protein that has three major functional domains: the $\mathrm{N}$-terminal domain (NTD), DNA-binding domain, and ligand-binding domain. The NTD, encoded by exon 1 , regulates the transactivation of target genes and contains two polymorphic trinucleotide repeats: CAG and GGC, encoding polyglutamine and polyglycine, respectively [71]. The length of the CAG repeats correlates inversely with the AR transactivation function [72, 73]. Moreover, Hakimi et al. and Irvine et al. associated a low number of CAG repeats with an increased risk of PC [74-78]. Furthermore, the variants reported in the CAG and GGC repeats are highly polymorphic and associated with ethnic factors; thus, it may be important to determine their association with PC in different populations. Trinucleotide repeats are associated with human diseases and microsatellite instability [79]. The last one affects gene expression and protein function [80]. In addition to PC, the polymorphic CAG repeats have been associated with skin disorders [81, 82], breast cancer, polycystic ovary disease, Kennedy syndrome [83, 84], azoospermia, and oligospermia [85]. Furthermore, the effects of the repetition sequence GGC polyglycine have been associated with hypospadias and cryptorchidism [86, 87]; however, its role in transcription is unclear.

According to Kittles et al. the CAG and GGC repeats specifically vary depending on the ethnic group [88, 89]. The normal distribution of the CAG repeats is reported in a range of 6-39, with an average of 19-20 in African Americans, 21-22 in Caucasians, 22-23 in Asians, and 23 in Hispanics [90]. However and regarding South American countries, Brazil reported an average of 20.65 CAGs [91]. Moreover, Madjunkova et al. reported a mean repeat length of 21.5 CAGs in patients with PC from Macedonia [92]. Beilin et al. examined prostate adenocarcinomas, and the number of CAG repeats ranged from 12 to 30 and averaged 20 , which was similar to that in a healthy Brazilian population [91]. Paz-y-Miño et al. reported that the repeat range in the mestizo control group was 16-30, with an average of 22, resembling Asians and Caucasians. The study was performed to determine the association between CAG and GGC repeats and the risk of PC and histopathological characteristics of prostate tumors. A total of 334 individuals were analyzed; 108 mestizo patients had a clinical diagnosis of prostate adenocarcinoma and 148 mestizo patients were healthy. Additionally, 78 healthy indigenous individuals were analyzed to determine the variety of trinucleotide repeats between different ethnic groups. The patient group presented with 12-30 repetitions with an average of 20 . The most common numbers of CAG repeats were 21 and 22 (15.7 and 12\%, resp.). The mestizo control group had 16-30 repetitions with an average of 22 . The most common numbers of CAG repeats were $22(25.7 \%)$ and $25(12.8 \%)$. In the indigenous population, the repeat size ranged from 18 to $29 \mathrm{CAGs}$, determining the highest average of the three groups corresponding to 24 repetitions. Thus, the most common numbers of CAG repeats were 24 and 26, both with $24.4 \%$. Statistically significant differences $(P<0.001)$ in the distribution of these trinucleotides were demonstrated ( $\geq 22$ CAGs versus $\leq 21$ CAGs). In relation to tumor clinical characteristics, the presence of $=21$ CAGs showed significant association with tumor stage (OR, 4.75; 95\% CI, 1.77-12.72; $P<0.05)$ and Gleason score (OR, 2.9; 95\% CI, 1.1-7.66; $P=0.03)$ as in the ratio of risk of prostate cancer [70].

The ranges and averages of the CAG and GGC repeats in control mestizo population are similar to those of Asian and Caucasian-European populations. This may occur because the mestizo Ecuadorian population is considered a trihybrid, containing genes originated from America and descendants of Native Asians, Europeans, and Africans [93]. Other polymorphisms associated with PC in Ecuador also showed similar frequencies to Asians [24, 40]. Additionally, these results were consistent with the average in cases (19 CAGs) and controls (19-20 CAGs) in African Americans (17 CAGs) and in both cases and controls (21.95 CAGs) in Australians [94].

Finally, these results indicated that in mestizos the PC risk increased 2.99 times in males with $\leq 21$ CAGs. By contrast, some studies did not identify an association with this repetition $[43,95,96]$. Several studies reported no association between the GGC repeat lengths, the PC risk, and pathological characteristics [34], stating that there were no significant differences between cases and controls [97]. Similarly, the risk of PC and the tumor characteristics did not differ in relation to the number of GGC repeats in this study [93].

\section{Conclusions}

Cancer research has evolved in parallel with cutting-edge technologies, leading to the development of a personalized genomic-based therapy. This tailored treatment not only takes into account the clinical aspects of each patient but also, and most importantly, the molecular characteristics of their tumors. Thus, to offer a precise anticancer therapy, personalized oncology identifies druggable cancer driver proteins based on their genomic alterations and differences between human populations. For instance, the 1000 Genomes' Project (Phase 3) demonstrates that the allele frequencies of the SRD5A2 V89L, SRD5A2 A49T, and MTHFR C677T genetic variants differ among the Latin American (Ecuador, Colombia, and Peru), Caucasian (Spain), and Asian (Japan, India, and China) populations. In conclusion, in order to implement successful pharmacogenomics tests at the hospitals in Ecuador, it is important to understand the genetic variability of the mestizo population. Likewise, genetic polymorphisms in the MTHFR, SRD5A2, and AR genes are associated with $\mathrm{PC}$ risk in high altitude mestizo Ecuadorian population.

\section{Conflicts of Interest}

The authors declare no conflicts of interest. 


\section{References}

[1] M. M. Kgatle, A. A. Kalla, M. M. Islam, M. Sathekge, and R. Moorad, "Prostate Cancer: Epigenetic Alterations, Risk Factors, and Therapy," Prostate Cancer, vol. 2016, Article ID 5653862, 11 pages, 2016.

[2] Cancer Research UK, Worldwide cancer statistics, Cancer statistics 2014, http://www.cancerresearchuk.org/cancerinfo/ cancerstats/world/.

[3] J. Ferlay, H. R. Shin, F. Bray, D. Forman, C. Mathers, and D. M. Parkin, "Estimates of worldwide burden of cancer in 2008: GLOBOCAN 2008," International Journal of Cancer, vol. 127, no. 12, pp. 2893-2917, 2010.

[4] A. Jemal, F. Bray, M. M. Center, J. Ferlay, E. Ward, and D. Forman, "Global cancer statistics," CA: A Cancer Journal for Clinicians, vol. 61, no. 2, pp. 69-90, 2011.

[5] M. S. Sierra, I. Soerjomataram, and D. Forman, "Prostate cancer burden in Central and South America," Cancer Epidemiology, vol. S44, pp. S131-S140, 2016.

[6] P. Cueva and J. Yépez, Cancer epidemiology in Quito, National Cancer Registry (NCR), Quito, Ecuador, 2009.

[7] World Health Organization: International Agency for Research on Cancer, GLOBOCAN 2012: Estimated cancer incidence, mortality and prevalence worldwide in 2012. http://globocan.iarc.fr/Default.aspx.

[8] C. Meldrum, M. A. Doyle, and R. W. Tothill, "Next-generation sequencing for cancer diagnostics: a practical perspective," Clinical Biochemist Reviews, vol. 32, no. 4, pp. 177-195, 2011.

[9] H. Beltran, R. Yelensky, G. Frampton et al., "Targeted nextgeneration sequencing of advanced prostate cancer identifies potential therapeutic targets and disease heterogeneity," European Urology, vol. 63, no. 5, pp. 920-926, 2013.

[10] D. Shyr and Q. Liu, "Next generation sequencing in cancer research and clinical application," Biological Procedures Online, vol. 15, no. 1, article no. 4, 2013.

[11] S. S. Yadav, J. Li, H. J. Lavery, K. K. Yadav, and A. K. Tewari, "Next-generation sequencing technology in prostate cancer diagnosis, prognosis, and personalized treatment," Urologic Oncology: Seminars and Original Investigations, vol. 33, no. 6, p. 267, 2015.

[12] H. Nakagawa, C. P. Wardell, M. Furuta, H. Taniguchi, and A. Fujimoto, "Cancer whole-genome sequencing: Present and future," Oncogene, vol. 34, no. 49, pp. 5943-5950, 2015.

[13] Z. Fang and X. Cui, "Design and validation issues in RNA-seq experiments," Briefings in Bioinformatics, vol. 12, no. 3, Article ID bbr004, pp. 280-287, 2011.

[14] D. Robinson, E. M. Van Allen, Y.-M. Wu et al., "Integrative Clinical Genomics of Advanced Prostate Cancer," Cell, vol. 161, no. 5, pp. 1215-1228, 2015.

[15] J. G. Lohr, V. A. Adalsteinsson, K. Cibulskis et al., "Wholeexome sequencing of circulating tumor cells provides a window into metastatic prostate cancer," Nature Biotechnology, vol. 32, no. 5, pp. 479-484, 2014.

[16] M. Berger, M. Lawrence, F. Demichelis et al., "The genomic complexity of primary human prostate cancer," Nature, vol. 470, no. 7333, pp. 214-220, 2011.

[17] P. Rajan, I. M. Sudbery, M. E. M. Villasevil et al., "Nextgeneration sequencing of advanced prostate cancer treated with androgen-deprivation therapy," European Urology, vol. 66, no. 1, pp. 32-39, 2014.
[18] S. Ren, Z. Peng, J. Mao et al., "RNA-seq analysis of prostate cancer in the Chinese population identifies recurrent gene fusions, cancer-associated long noncoding RNAs and aberrant alternative splicings," Cell Research, vol. 22, no. 5, pp. 806-821, 2012.

[19] D. Miyamoto, Y. Zheng, B. Wittner et al., "RNA-Seq of single prostate CTCs implicates noncanonical Wnt signaling in antiandrogen resistance," Science, vol. 349, no. 6254, pp. 13511356, 2015.

[20] C. Barbieri, S. Baca, M. Lawrence et al., "Exome sequencing identifies recurrent SPOP, FOXA1 and MED12 mutations in prostate cancer," Nature Genetics, vol. 44, no. 6, pp. 685-689, 2012.

[21] B. S. Taylor, N. Schultz, H. Hieronymus et al., "Integrative genomic profiling of human prostate cancer," Cancer Cell, vol. 18, no. 1, pp. 11-22, 2010.

[22] J. Gudmundsson, P. Sulem, D. F. Gudbjartsson et al., "A study based on whole-genome sequencing yields a rare variant at $8 \mathrm{q} 24$ associated with prostate cancer," Nature Genetics, vol. 44 , no. 12 , pp. 1326-1329, 2012.

[23] S. C. Baca, D. Prandi, M. S. Lawrence et al., "Punctuated evolution of prostate cancer genomes," Cell, vol. 153, no. 3, pp. 666677, 2013

[24] C. Paz-y-Miño, T. Witte, P. Robles, W. Llumipanta, M. Díaz, and M. Arévalo, "Association among polymorphisms in the steroid $5 \alpha$-reductase type II (SRD5A2) gene, prostate cancer risk, and pathologic characteristics of prostate tumors in an Ecuadorian population," Cancer Genetics and Cytogenetics, vol. 189, no. 2, pp. 71-76, 2009.

[25] R. K. Ross, M. C. Pike, G. A. Coetzee et al., "Androgen metabolism and prostate cancer: Establishing a model of genetic susceptibility," Cancer Research, vol. 58, no. 20, pp. 4497-4504, 1998.

[26] A. W. Hsing, A. P. Chokkalingam, C. Chen et al., "Polymorphic markers in the SRD5A2 gene and prostate cancer risk: A population-based case-control study," Cancer Epidemiology Biomarkers and Prevention, vol. 10, no. 10, pp. 1077-1082, 2001.

[27] A. S. Singh, C. H. Chau, D. K. Price, and W. D. Figg, "Mechanisms of disease: Polymorphisms of androgen regulatory genes in the development of prostate cancer," Nature Clinical Practice Urology, vol. 2, no. 2, pp. 101-107, 2005.

[28] N. Makridakis, R. K. Ross, M. C. Pike et al., "A prevalent missense substitution that modulates activity of prostatic steroid $5 \alpha$-reductase," Cancer Research, vol. 57, no. 6, pp. 1020-1022, 1997.

[29] N. M. Makridakis, R. K. Ross, M. C. Pike et al., "Association of mis-sense substitution in SRD5A2 gene with prostate cancer in African-American and Hispanic men in Los Angeles, USA," The Lancet, vol. 354, no. 9183, pp. 975-978, 1999.

[30] R. K. Nam, A. Toi, D. Vesprini et al., "V89L polymorphism of type-2, 5-alpha reductase enzyme gene predicts prostate cancer presence and progression," Urology, vol. 57, no. 1, pp. 199-204, 2001.

[31] Z. Li, T. Habuchi, K. Mitsumori et al., "Association of V89L SRD5A2 polymorphism with prostate cancer development in a Japanese population," Journal of Urology, vol. 169, no. 6, pp. 2378-2381, 2003.

[32] K. Margiotti, F. Sangiuolo, A. De Luca et al., "Evidence for an association between the SRD5A2 (type II steroid $5 \alpha$-reductase) locus and prostate cancer in Italian patients," Disease Markers, vol. 16, no. 3-4, pp. 147-150, 2000. 
[33] N. M. Makridakis, E. Di Salle, and J. K. V. Reichardt, "Biochemical and pharmacogenetic dissection of human steroid $5 \alpha$ reductase type II," Pharmacogenetics, vol. 10, no. 5, pp. 407-413, 2000.

[34] M. S. Cicek, D. V. Conti, A. Curran et al., "Association of Prostate Cancer Risk and Aggressiveness to Androgen Pathway Genes: SRD5A2, CYP17, and the AR," Prostate, vol. 59, no. 1, pp. 69-76, 2004.

[35] T. Söderström, M. Wadelius, S.-O. Andersson et al., " $5 \alpha$ reductase 2 polymorphisms as risk factors in prostate cancer," Pharmacogenetics, vol. 12, no. 4, pp. 307-312, 2002.

[36] A. Shibata, M. I. Garcia, I. Cheng et al., "Polymorphisms in the androgen receptor and type II $5 \alpha$-reductase genes and prostate cancer prognosis," Prostate, vol. 52, no. 4, pp. 269-278, 2002.

[37] M. S. Forrest, S. M. Edwards, R. Houlston et al., "Association between hormonal genetic polymorphisms and early-onset prostate cancer," Prostate Cancer and Prostatic Diseases, vol. 8, no. 1, pp. 95-102, 2005.

[38] J. M. Jaffe, S. B. Malkowicz, A. H. Walker et al., "Association of SRD5A2 genotype and pathological characteristics of prostate tumors," Cancer Research, vol. 60, no. 6, pp. 1626-1630, 2000.

[39] The 1000 Genomes Project Consortium, "A global reference for human genetic variation," Nature, vol. 526, no. 7571, pp. 68-74, 2015.

[40] A. López-Cortés, G. Jaramillo-Koupermann, M. J. Muñoz et al., "Genetic polymorphisms in MTHFR (C677T, A1298C), MTR (A2756G) and MTRR (A66G) genes associated with pathological characteristics of prostate cancer in the ecuadorian population," The American Journal of the Medical Sciences, vol. 346, no. 6, pp. 447-454, 2013.

[41] J.-L. Bai, M.-H. Zheng, X. Xia, M. Ter-Minassian, Y.-P. Chen, and F. Chen, "MTHFR C677T polymorphism contributes to prostate cancer risk among Caucasians: A meta-analysis of 3511 cases and 2762 controls," European Journal of Cancer, vol. 45, no. 8, pp. 1443-1449, 2009.

[42] M. H. Muslumanoglu, E. Tepeli, S. Demir et al., "The analysis of the relationship between A1298C and C677T polymorphisms of the MTHFR gene with prostate cancer in Eskisehir population.," Genetic testing and molecular biomarkers, vol. 13, no. 5, pp. 641645, 2009.

[43] M. S. Cicek, N. L. Nock, L. Li, D. V. Conti, G. Casey, and J. S. Witte, "Relationship between methylenetetrahydrofolate reductase C677T and A1298C genotypes and haplotypes and prostate cancer risk and aggressiveness," Cancer Epidemiology Biomarkers and Prevention, vol. 13, no. 8, pp. 1331-1336, 2004.

[44] R. Singal, L. Ferdinand, P. M. Das, I. M. Reis, and J. J. Schlesselman, "Polymorphisms in the methylenetetrahydrofolate reductase gene and prostate cancer risk.," International journal of oncology, vol. 25, no. 5, pp. 1465-1471, 2004.

[45] S. Michael, R. Qamar, F. Akhtar, W. A. Khan, and A. Ahmed, "C677T polymorphism in the methylenetetrahydrofolate reductase gene is associated with primary closed angle glaucoma," Molecular Vision, vol. 14, pp. 661-665, 2008.

[46] R. Hubner, K. Muir, and J. Lui, "Folate metabolism polymorphisms influence risk of colorectal adenoma recurrence, Cancer Epidemiology," Biomarkers Prevention, vol. 15, no. 9, pp. 1607-1613, 2006.

[47] B. Heijmans, J. M. Boer, and H. E. Suchiman, "A common variant of the methylenetetrahydrofolate reductase gene (1q36) is associated with an increased risk of cancer," Cancer Research, vol. 63, no. 6, pp. 1249-1253, 2003.
[48] A. Wilson, R. Platt, Q. Wu et al., "A common variant in methionine synthase reductase combined with low cobalamin (Vitamin B12) increases risk for spina bifida," Molecular Genetics and Metabolism, vol. 67, no. 4, pp. 317-323, 1999.

[49] M. Johansson, B. Van Guelpen, J. Hultdin et al., “The MTHFR $677 \mathrm{C} \rightarrow \mathrm{T}$ polymorphism and risk of prostate cancer: Results from the CAPS study," Cancer Causes and Control, vol. 18, no. 10, pp. 1169-1174, 2007.

[50] C. A. Hobbs, S. L. Sherman, P. Yi et al., "Polymorphisms in genes involved in folate metabolism as maternal risk factors for down syndrome," The American Journal of Human Genetics, vol. 67, no. 3, pp. 623-630, 2000.

[51] V. Dhillon, P. Thomas, and M. Fenech, "Effect of common polymorphisms in folate uptake and metabolism genes on frequency of micronucleated lymphocytes in a South Australian cohort," Mutation Research - Fundamental and Molecular Mechanisms of Mutagenesis, vol. 665, no. 1-2, pp. 1-6, 2009.

[52] A. Ulvik and P. M. Ueland, "Single nucleotide polymorphism (SNP) genotyping in unprocessed whole blood and serum by real-time PCR: Application to SNPs affecting homocysteine and folate metabolism," Clinical Chemistry, vol. 47, no. 11, pp. 20502053, 2001.

[53] L. B. Bailey and J. F. Gregory III, "Polymorphisms of methylenetetrahydrofolate reductase and other enzymes: metabolic significance, risks and impact on folate requirement," Journal of Nutrition, vol. 129, no. 5, pp. 919-922, 1999.

[54] P. M. Das and R. Singal, "DNA methylation and cancer," Journal of Clinical Oncology, vol. 22, no. 22, pp. 4632-4642, 2004.

[55] R. Gershoni-Baruch, E. Dagan, D. Israeli, L. Kasinetz, E. Kadouri, and E. Friedman, "Association of the C677T polymorphism in the MTHFR gene with breast and/or ovarian cancer risk in Jewish women," European Journal of Cancer, vol. 36, no. 18, pp. 2313-2316, 2000.

[56] C. Song, D. Xing, W. Tan, Q. Wei, and D. Lin, "Methylenetetrahydrofolate reductase polymorphisms increase risk of esophageal squamous cell carcinoma in a Chinese population," Cancer Research, vol. 61, no. 8, pp. 3272-3275, 2001.

[57] X. Miao, D. Xing, W. Tan, J. Qi, W. Lu, and D. Lin, "Susceptibility to gastric cardia adenocarcinoma and genetic polymorphisms in methylenetetrahydrofolate reductase in an at-risk Chinese population," Cancer Epidemiology Biomarkers and Prevention, vol. 11, no. 11, pp. 1454-1458, 2002.

[58] F. Kimura, K. H. Franke, C. Steinhoff et al., "Methyl group metabolism gene polymorphisms and susceptibility to prostatic carcinoma," Prostate, vol. 45, no. 3, pp. 225-231, 2000.

[59] J. L. Wiemels, R. N. Smith, G. M. Taylor, O. B. Eden, F. E. Alexander, and M. F. Greaves, "Methylenetetrahydrofolate reductase (MTHFR) polymorphisms and risk of molecularly defined subtypes of childhood acute leukemia," Proceedings of the National Academy of Sciences of the United States of America, vol. 98, no. 7, pp. 4004-4009, 2001.

[60] J. Chen, E. Giovannucci, K. Kelsey et al., "A methylenetetrahydrofolate reductase polymorphism and the risk of colorectal cancer," Cancer Research, vol. 56, no. 21, pp. 4862-4864, 1996.

[61] P. A. Humphrey, "Gleason grading and prognostic factors in carcinoma of the prostate," Modern Pathology, vol. 17, no. 3, pp. 292-306, 2004.

[62] J. Chen, E. Giovannucci, S. E. Hankinson et al., "A prospective study of methylenetetrahydrofolate reductase and methionine synthase gene polymorphisms, and risk of colorectal adenoma," Carcinogenesis, vol. 19, no. 12, pp. 2129-2132, 1998. 
[63] T. V. Pereira, M. Rudnicki, A. C. Pereira, M. S. Pombo-DeOliveira, and R. F. Franco, "5,10-Methylenetetrahydrofolate reductase polymorphisms and acute lymphoblastic leukemia risk: A meta-analysis," Cancer Epidemiology Biomarkers and Prevention, vol. 15, no. 10, pp. 1956-1963, 2006.

[64] S. Yegnasubramanian, J. Kowalski, M. L. Gonzalgo et al., "Hypermethylation of CpG Islands in Primary and Metastatic Human Prostate Cancer," Cancer Research, vol. 64, no. 6, pp. 1975-1986, 2004.

[65] L. Sharp and J. Little, "Polymorphisms in Genes Involved in Folate Metabolism and Colorectal Neoplasia: A HuGE Review," American Journal of Epidemiology, vol. 159, no. 5, pp. 423-443, 2004.

[66] K. Robien and C. M. Ulrich, "5,10-Methylenetetrahydrofolate reductase polymorphisms and leukemia risk: A HuGE minireview," American Journal of Epidemiology, vol. 157, no. 7, pp. 571$582,2003$.

[67] H. Shen, Y. Xu, Y. Zheng et al., "Polymorphisms of 5,10methylenetetrahydrofolate reductase and risk of gastric cancer in a Chinese population: a case-control study," International Journal of Cancer, vol. 95, no. 5, pp. 332-336, 2001.

[68] C. Marchal, M. Redondo, A. Reyes-Engel et al., "Association between polymorphisms of folate-metabolizing enzymes and risk of prostate cancer," European Journal of Surgical Oncology, vol. 34, no. 7, pp. 805-810, 2008.

[69] B. R. Van Guelpen, S. M. Wirén, A. R. J. Bergh, G. Hallmans, P. E. Stattin, and J. Hultdin, "Polymorphisms of methylenetetrahydrofolate reductase and the risk of prostate cancer: A nested case-control study," European Journal of Cancer Prevention, vol. 15, no. 1, pp. 46-50, 2006.

[70] C. Paz-Y-Miño, P. Robles, C. Salazar et al., "Positive association of the androgen receptor CAG repeat length polymorphism with the risk of prostate cancer," Molecular Medicine Reports, vol. 14, no. 2, pp. 1791-1798, 2016.

[71] H. F. B. M. Sleddens, B. A. Oostra, A. O. Brinkmann, and J. Trapman, "Trinucleotide (GGN) repeat polymorphism in the human androgen receptor (AR) gene," Human Molecular Genetics, vol. 2, no. 4, p. 493, 1993.

[72] D. J. Mangelsdorf, C. Thummel, M. Beato et al., "The nuclear receptor super-family: the second decade," Cell, vol. 83, no. 6 , pp. 835-839, 1995.

[73] T. G. Tut, F. J. Ghadessy, M. A. Trifiro, L. Pinsky, and E. L. Yong, "Long polyglutamine tracts in the androgen receptor are associated with reduced trans-activation, impaired sperm production, and male infertility," Journal of Clinical Endocrinology and Metabolism, vol. 82, no. 11, pp. 3777-3782, 1997.

[74] R. A. Irvine, G. A. Coetzee, M. C. Yu, and R. K. Ross, “The CAG and GGC Microsatellites of the Androgen Receptor Gene Are in Linkage Disequilibrium in Men with Prostate Cancer," Cancer Research, vol. 55, no. 9, pp. 1937-1940, 1995.

[75] E. Giovannucci, M. J. Stampfer, K. Krithivas et al., "The CAG repeat within the androgen receptor gene and its relationship to prostate cancer," Proceedings of the National Academy of Sciences of the United States of America, vol. 94, no. 3320-3323, 1997.

[76] S. A. Ingles, R. K. Ross, M. C. Yu et al., "Association of prostate cancer risk with genetic polymorphisms in vitamin $\mathrm{D}$ receptor and androgen receptor," Journal of the National Cancer Institute, vol. 89, no. 2, pp. 166-170, 1997.

[77] J. L. Stanford, J. J. Just, M. Gibbs et al., "Polymorphic repeats in the androgen receptor gene: Molecular markers of prostate cancer risk," Cancer Research, vol. 57, no. 6, pp. 1194-1198, 1997.
[78] J. M. Hakimi, M. P. Schoenberg, R. H. Rondinelli, S. Piantadosi, and E. R. Barrack, "Androgen receptor variants with short glutamine or glycine repeats may identify unique subpopulations of men with prostate cancer," Clinical Cancer Research, vol. 3, no. 9, pp. 1599-1608, 1997.

[79] H. Ellegren, "Microsatellites: simple sequences with complex evolution," Nature Reviews Genetics, vol. 5, no. 6, pp. 435-445, 2004.

[80] M. M. Albà and R. Guigó, "Comparative analysis of amino acid repeats in rodents and humans," Genome Research, vol. 14, no. 4, pp. 549-554, 2004.

[81] M. E. Sawaya and A. R. Shalita, "Androgen receptor polymorphisms (CAG repeat lengths) in androgenetic alopecia, hirsutism, and acne," Journal of Cutaneous Medicine and Surgery, vol. 3, no. 9-15, 1998.

[82] N. A. Shah, H. J. Antoine, M. Pall, K. D. Taylor, R. Azziz, and M. O. Goodarzi, "Association of androgen receptor CAG repeat polymorphism and polycystic ovary syndrome," Journal of Clinical Endocrinology and Metabolism, vol. 93, no. 5, pp. 1939-1945, 2008.

[83] P. Mehdipour, S. Pirouzpanah, M. Kheirollahi, and M. Atri, "Androgen receptor gene CAG repeat polymorphism and breast cancer risk in Iranian women: a case-control study," Breast Journal, vol. 17, no. 1, pp. 39-46, 2011.

[84] H. E. MacLean, W.-T. Choi, G. Rekaris, G. L. Warne, and J. D. Zajac, "Abnormal androgen receptor binding affinity in subjects with Kennedy's disease (spinal and bulbar muscular atrophy)," Journal of Clinical Endocrinology and Metabolism, vol. 80, no. 2, pp. 508-516, 1995.

[85] O. A. Fesaǐ, S. A. Kravchenko, M. I. Tyrkus et al., "Androgen receptor CAG gene polymorphism in men with azoospermia and oligozoospermia in Ukraine," T Sitologii a i genetika, vol. 43, no. 6, pp. 45-51, 2009.

[86] R. Radpour, M. Rezaee, A. Tavasoly, S. Solati, and A. Saleki, "Association of long polyglycine tracts (GGN Repeats) in exon 1 of the androgen receptor gene with cryptorchidism and penile hypospadias in Iranian patients," Journal of Andrology, vol. 28, no. 1, pp. 164-169, 2007.

[87] E. L. Aschim, A. Nordenskjöld, A. Giwercman et al., "Linkage between cryptorchidism, hypospadias, and GGN repeat length in the androgen receptor gene," Journal of Clinical Endocrinology and Metabolism, vol. 89, no. 10, pp. 5105-5109, 2004.

[88] O. Sartor, Q. Zheng, and J. A. Eastham, "Androgen receptor gene CAG repeat length varies in a race-specific fashion in men without prostate cancer," Urology, vol. 53, no. 2, pp. 378-380, 1999.

[89] R. A. Kittles, D. Young, S. Weinrich et al., "Extent of linkage disequilibrium between the androgen receptor gene CAG and GGC repeats in human populations: Implications for prostate cancer risk," Human Genetics, vol. 109, no. 3, pp. 253-261, 2001.

[90] C. Krausz, "An encore for the repeats: New insights into an old genetic variant," Journal of Clinical Endocrinology and Metabolism, vol. 97, no. 3, pp. 764-767, 2012.

[91] M. L. Ribeiro, A. Santos, A. B. Carvalho-Salles, and C. Hackel, "Allelic frequencies of six polymorphic markers for risk of prostate cancer," Brazilian Journal of Medical and Biological Research, vol. 35, no. 2, pp. 205-213, 2002.

[92] S. Madjunkova, A. Eftimov, V. Georgiev, D. Petrovski, A. J. Dimovski, and D. Plaseska-Karanfilska, "Cag repeat number in the androgen receptor Gene and Prostate Cancer," Balkan Journal of Medical Genetics, vol. 15, no. 1, pp. 31-36, 2012. 
[93] M. Baeta, C. Núñez, J. M. Aznar et al., "Analysis of 10 X-STRs in three population groups from Ecuador," Forensic Science International: Genetics, vol. 7, no. 1, pp. e19-e20, 2013.

[94] J. Beilin, L. Harewood, M. Frydenberg et al., "A case-control study of the androgen receptor gene CAG repeat polymorphism in Australian prostate carcinoma subjects," Cancer, vol. 92, no. 4, pp. 941-949, 2001.

[95] E. M. Lange, H. Chen, K. Brierley et al., "The polymorphic exon 1 androgen receptor CAG repeat in men with a potential inherited predisposition to prostate cancer," Cancer Epidemiology Biomarkers and Prevention, vol. 9, no. 4, pp. 439-442, 2000.

[96] D. K. Price, C. H. Chau, C. Till et al., "Androgen receptor CAG repeat length and association with prostate cancer risk: Results from the prostate cancer prevention trial," Journal of Urology, vol. 184, no. 6, pp. 2297-2302, 2010.

[97] D. Alptekin, M. Izmirli, Y. Bayazit et al., "Evaluation of the effects of androgen receptor gene trinucleotide repeats and prostate-specific antigen gene polymorphisms on prostate cancer," Genetics and Molecular Research, vol. 11, no. 2, pp. 14241432, 2012. 


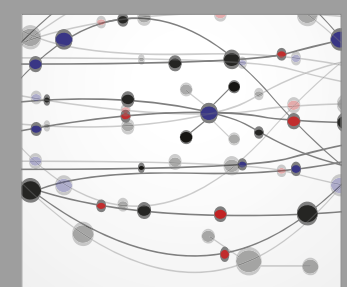

The Scientific World Journal
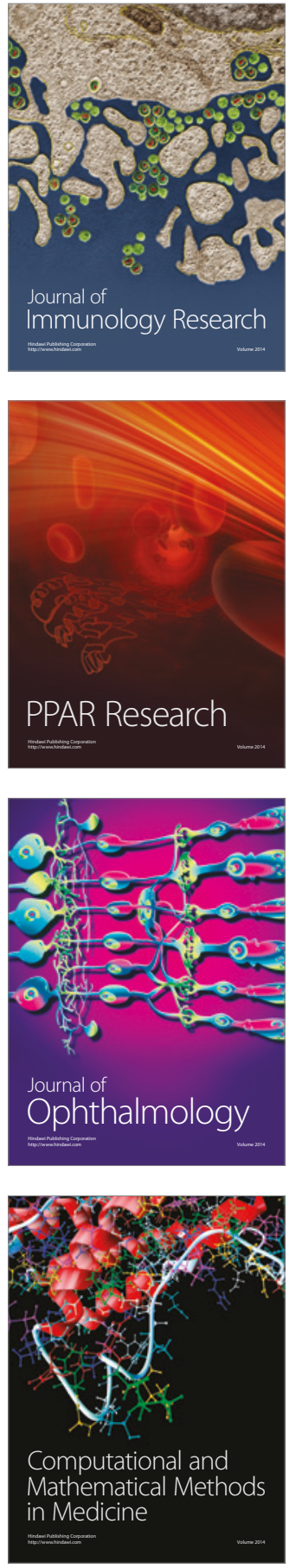

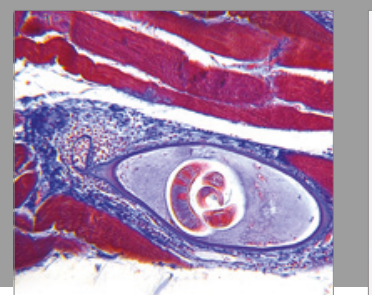

Gastroenterology Research and Practice
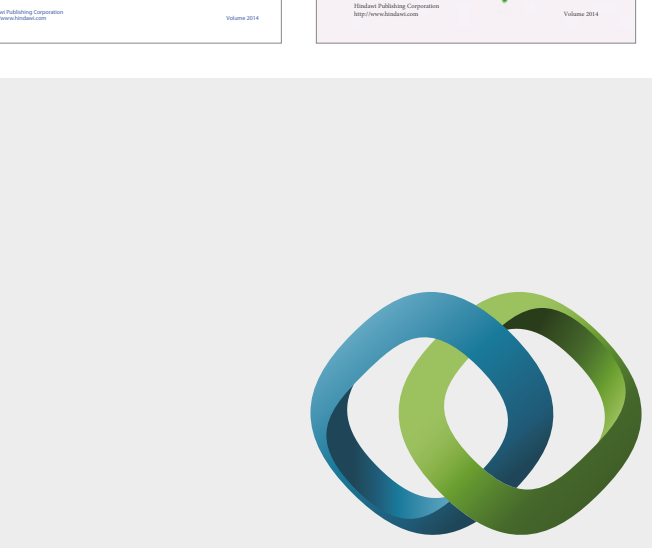

\section{Hindawi}

Submit your manuscripts at

https://www.hindawi.com
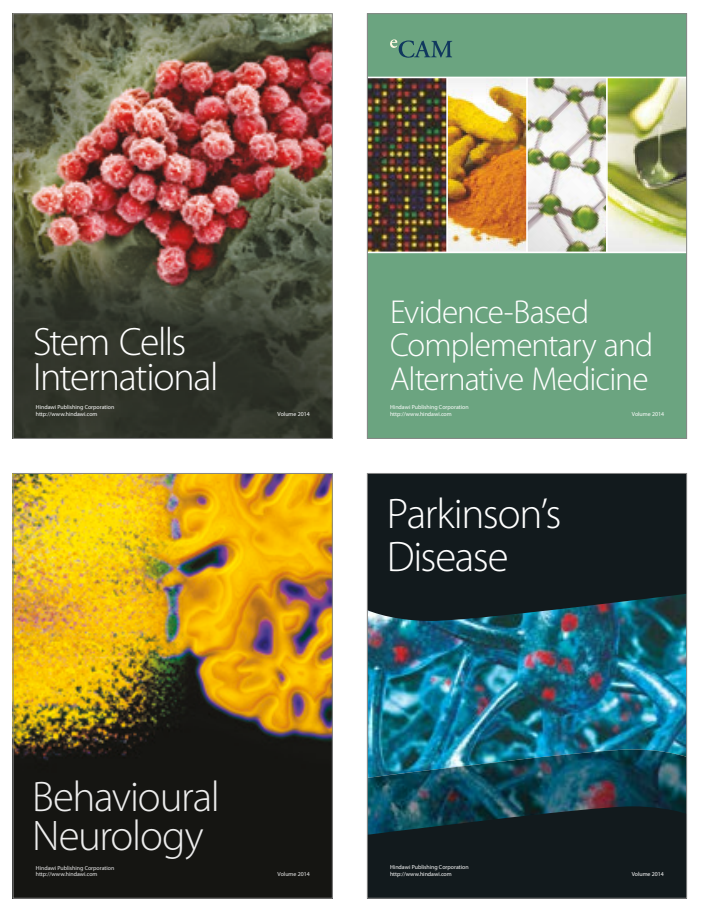
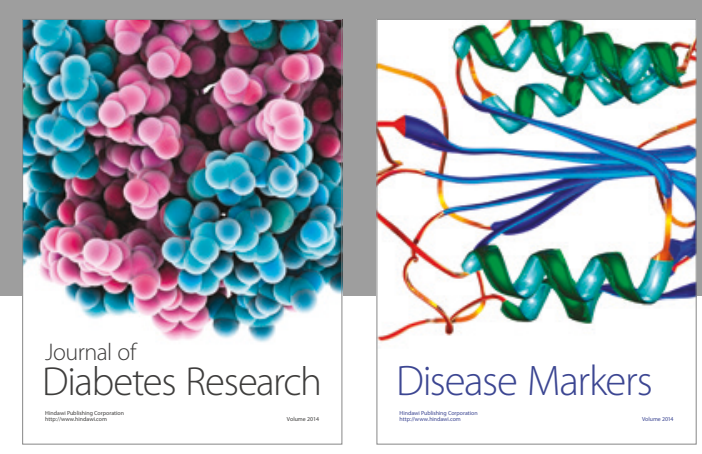

Disease Markers
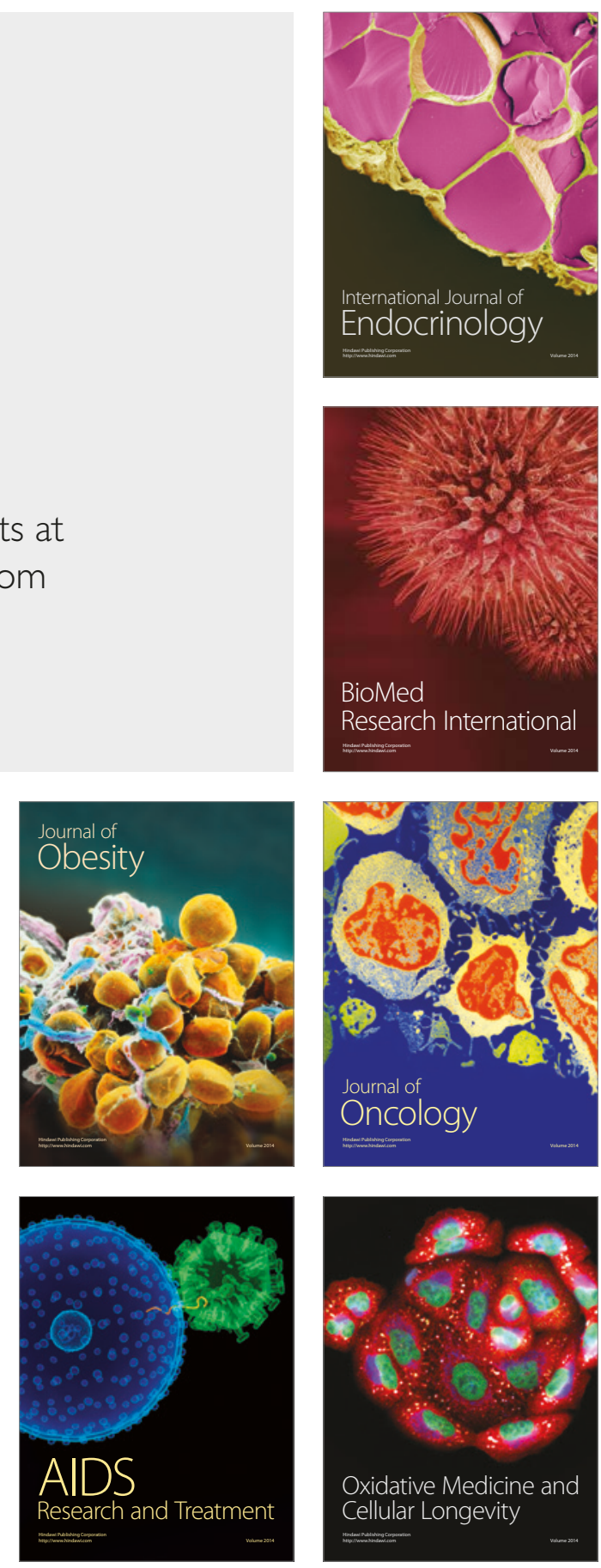